\title{
High- and low-level pressure support during walking in people with severe kyphoscoliosis
}

\author{
C. Menadue*,\#, J.A. Alison*,\# A.J. Piper*, ", K.K. Wong*," , C. Hollier*,\# and E.R. Ellis"
}

ABSTRACT: To determine whether the level of pressure support (PS) provided during exercise influences endurance time in people with severe kyphoscoliosis, a double-blind randomised crossover study was performed. We hypothesised that high-level PS would be required to enhance endurance time in this population with high impedance to inflation.

13 participants with severe kyphoscoliosis performed four endurance treadmill tests in random order: unassisted; with sham PS; low-level PS of $10 \mathrm{cmH}_{2} \mathrm{O}$ (PS 10); and high-level PS of $20 \mathrm{cmH}_{2} \mathrm{O}$ (PS 20). Participants and assessors were blinded to the level of PS delivered during exercise.

Endurance time was greater with PS 20 (median (interquartile range) 217 (168-424) s) compared with unassisted exercise (139 (111-189) s), sham PS (103 (88-155) s) and PS 10 (159 (131-206) s). In addition, isotime respiratory rate was decreased by 8 breaths $\mathrm{min}^{-1}(95 \% \mathrm{Cl}$ 11- -5 breaths $\left.\cdot \mathrm{min}^{-1}\right)$ and isotime oxygen saturation increased by $4 \%(95 \% \mathrm{CI} 1-7 \%)$ with PS 20 compared with unassisted exercise.

People with severe kyphoscoliosis require high-level PS during walking to improve exercise performance. Investigation of high-level PS as an adjunct to exercise training or to assist in the performance of daily activities is warranted.

KEYWORDS: Chronic respiratory failure, exercise, hypercapnia, neuromuscular and chest wall disorders, non-invasive ventilation

ndividuals with severe kyphoscoliosis commonly have a ventilatory limitation to exercise [1] and report severe exertional dyspnoea [2]. Unfortunately there are limited strategies available that improve exercise capacity in this population. Supplemental oxygen $\left(\mathrm{O}_{2}\right)$ during walking was shown to improve dyspnoea and oxygen saturation measured by pulse oximetry $\left(\mathrm{Sp}_{\mathrm{p}} \mathrm{O}_{2}\right)$ in moderate to severe kyphoscoliosis although exercise capacity did not increase [3]. In contrast, nocturnal noninvasive ventilatory support was associated with improvements in exercise performance in the absence of exercise training in people with chronic hypercapnic respiratory failure (HRF) secondary to severe kyphoscoliosis [4, 5]. However activity levels [6] and exercise capacity [7] remained well below normal, placing these individuals at risk of further deconditioning, which may impact the performance of daily activities.

The effect of noninvasive ventilation (NIV) during exercise in severe kyphoscoliosis is unclear. Pressure support (PS) of $10-14 \mathrm{cmH}_{2} \mathrm{O}$ during treadmill walking reduced distance walked compared with unassisted exercise [8], whereas PS of $19 \mathrm{cmH}_{2} \mathrm{O}$ during constant work rate cycling increased endurance time compared with unassisted exercise [2]. Whether the level of PS provided during exercise has an effect on the efficacy of PS during exercise is unknown. The aim of the present study was to determine the effect of high-level, low-level and sham PS during treadmill walking on endurance time compared with walking unassisted in patients with severe kyphoscoliosis already established on domiciliary NIV. We hypothesised that highlevel PS would be required to increase exercise endurance time due to the high impedance to chest wall inflation commonly observed in this population. If high-level PS during treadmill walking can improve exercise performance, it may have a role during exercise training or in assisting people with severe kyphoscoliosis to perform everyday activities.

\section{AFFILIATIONS}

*Dept of Respiratory and Sleep Medicine, Royal Prince Alfred Hospital,

\#Discipline of Physiotherapy, The University of Sydney, and

"Woolcock Institute of Medical Research, The University of Sydney, Sydney, Australia.

CORRESPONDENCE

C. Menadue

Dept of Respiratory and Sleep Medicine

Royal Prince Alfred Hospital

Missenden Rd

Camperdown

NSW 2050

Australia

E-mail: collette@med.usyd.edu.au

Received:

July 202009

Accepted after revision:

Dec 232009

First published online:

Jan 142010 


\section{METHOD}

\section{Participants}

Individuals aged 18 yrs or older with severe kyphoscoliosis were recruited from our home ventilation programme. Kyphoscoliosis was defined as "severe" if chronic HRF was present as a result of chest wall restriction. Exclusion criteria included: medically unstable over the past month requiring hospitalisation; resting arterial $\mathrm{pH}<7.35$; temperature $>38^{\circ} \mathrm{C}$; resting systolic blood pressure $<90$ or $>160 \mathrm{mmHg}$, diastolic blood pressure $<60$ or $>100 \mathrm{mmHg}$; myocardial infarction or unstable angina during the previous month; resting pulse rate $>120$ beats $\cdot \mathrm{min}^{-1}$; orthopaedic or neurological disorders that were likely to limit walking ability.

\section{Study design and protocol}

A randomised, double-blind, crossover study with repeated measures was conducted. Four endurance treadmill exercise tests were performed in random order: unassisted; sham PS (continuous positive airway pressure (CPAP) $4 \mathrm{cmH}_{2} \mathrm{O}$ ); lowlevel PS at $10 \mathrm{cmH}_{2} \mathrm{O}$ (PS 10); and high-level PS at $10 \mathrm{cmH}_{2} \mathrm{O}$ (PS 20). The randomisation scheme was generated using the website www.Randomization.com and test order was concealed in a sealed opaque envelope until written informed consent was obtained. For the three tests with PS, both participants and the assessors were blinded to the level of PS provided. Participants were told that bilevel machine settings would be different for each test with PS and that the best way to set the machine, or whether the machine was better than unassisted exercise, was unknown. The level of PS was set on the bilevel machine by one investigator and the settings were concealed. The investigator did not interact with participants or assessors during the tests. Participants received standardised encouragement each minute during the test.

Prior to each treadmill test, participants rested for 5 min while breathing under the conditions of the next test intervention. In addition, participants rested for $\geqslant 30 \mathrm{~min}$ between treadmill tests and until $\mathrm{Sp}_{\mathrm{p}} \mathrm{O}_{2}$, heart rate, dyspnoea, perceived exertion (leg fatigue) and blood pressure (BP) had returned to baseline. The study protocol and measures are displayed in figure 1. Endurance time, the reason for exercise cessation and the primary symptom that limited exercise were recorded. If $\mathrm{Sp}, \mathrm{O}_{2}$ was $<89 \%$ at rest, supplemental $\mathrm{O}_{2}$ was added to achieve a $\mathrm{Sp}, \mathrm{O}_{2}$ of $90-93 \%$, and was not adjusted further during exercise. Ethical approval was obtained from the Human Ethics Committee of Sydney South West Area Health Service and The University of Sydney, Sydney Australia. The study was registered with the Australian New Zealand Clinical Trials Registry (ACTRN12608000155392).

\section{Endurance treadmill test}

The treadmill test was an externally paced, constant work rate, endurance test. Walking speed was set at $80 \%$ of the average walking speed achieved during a 2-min walk test (2MWT) [9] that was performed $\geqslant 1 \mathrm{~h}$ prior to the treadmill tests. Participants were familiarised to the walking speed for $\sim 20 \mathrm{~s}, \geqslant 30 \mathrm{~min}$ before the first treadmill test. The speed remained consistent across the four tests. The treadmill test ceased if the participant felt too breathless or fatigued to continue, or if $\mathrm{Sp}_{\mathrm{p}} \mathrm{O}_{2}$ fell below $75 \%$.

\section{Measures}

Participant characteristics

Anthropometric data was recorded and a daytime resting arterial blood sample was analysed (Radiometer ABL700; Radiometer Medical, Copenhagen, Denmark). Pulmonary function tests were performed: spirometry; static lung volumes; maximum voluntary ventilation (MVV) measured over $12 \mathrm{~s}$ (Sensormedics, 6200 Autobox; Sensormedics Corporation, Yorba Linda, CA, USA); and maximum inspiratory and expiratory mouth occlusion pressures from residual volume and total lung capacity, respectively (Morgan Medical Ltd, Gillingham, UK). All measured values were compared to reference values [10-13]. Arm span was used to calculate per cent predicted values [14]

\section{Exercise}

Oxygen saturation and heart rate were measured via a finger probe (Radical; Masimo, Irvine, CA, USA). Measurements of $\mathrm{pH}$, partial pressure of carbon dioxide $\left(\mathrm{PCO}_{2}\right)$ and lactate were obtained from arterialised venous blood samples; refer to the online supplementary material for further details. Blood pressure was measured manually. Rate of perceived exertion (RPE), which reflected leg muscle exertion, and dyspnoea were measured on a $0-10$ category ratio scale [15].

Expiratory flow was measured via a mesh screen pneumotachograph (3830B; Hans Rudolph, Shawnee, KS, USA) placed between the oronasal mask and the expiratory port within the bilevel circuit. Data were collected at a sampling frequency of $100 \mathrm{~Hz}$. During unassisted exercise, flow was also measured using the oronasal mask and pneumotachograph in order to keep dead space $(195 \mathrm{~mL})$ consistent between the interventions. If participants could not tolerate the oronasal mask during unassisted exercise, ventilation was measured via a mouthpiece system (dead space $100 \mathrm{~mL}$ ). Respiratory rate was measured during the final $20 \mathrm{~s}$ of the baseline period, isotime exercise and the end of exercise.

\section{Pressure support}

PS was delivered via an oronasal mask (Ultra-Mirage Full Face Mask $^{\mathrm{TM}}$; ResMed, Sydney, Australia) using a pressure preset bilevel machine (VPAPIII STA ${ }^{\mathrm{TM}}$; ResMed) set in the spontaneous mode. The expiratory port on the mask was sealed and the mask elbow removed to allow attachment of a mesh screen pneumotachograph. An expiratory port (Ultra-Mirage Nasal Mask $^{\mathrm{TM}}$ elbow; ResMed) was placed after the pneumotachograph. During sham PS, the device was set at CPAP $4 \mathrm{cmH}_{2} \mathrm{O}$. For PS 10 and PS 20, expiratory positive airway pressure was set at $4 \mathrm{cmH}_{2} \mathrm{O}$, and PS was set at $10 \mathrm{cmH}_{2} \mathrm{O}$ or $20 \mathrm{cmH}_{2} \mathrm{O}$ above this, respectively. The inspiratory trigger threshold was set to "high" $\left(2.5 \mathrm{~L} \cdot \mathrm{min}^{-1}\right)$, rise time to $100 \mathrm{~ms}$, inspiratory positive airway pressure (IPAP) maximum $1.3 \mathrm{~s}$ and IPAP minimum $0.1 \mathrm{~s}$. The maximum inspiratory flow rate capacity was $>220 \mathrm{~L} \cdot \mathrm{min}^{-1}$.

\section{Data analysis and statistics}

An estimate of the required sample size was calculated using data from the first five participants. To detect a 60-s (equivalent to $50 \%$ ) change in endurance time with PS, using a standard deviation estimate of $49 \mathrm{~s}$, power of 0.8 , and $\alpha$ of 0.05 , a sample of 13 participants was required. SPSS Version 14.0 statistical software (SPSS Inc., Chicago, IL, USA) was used for data 


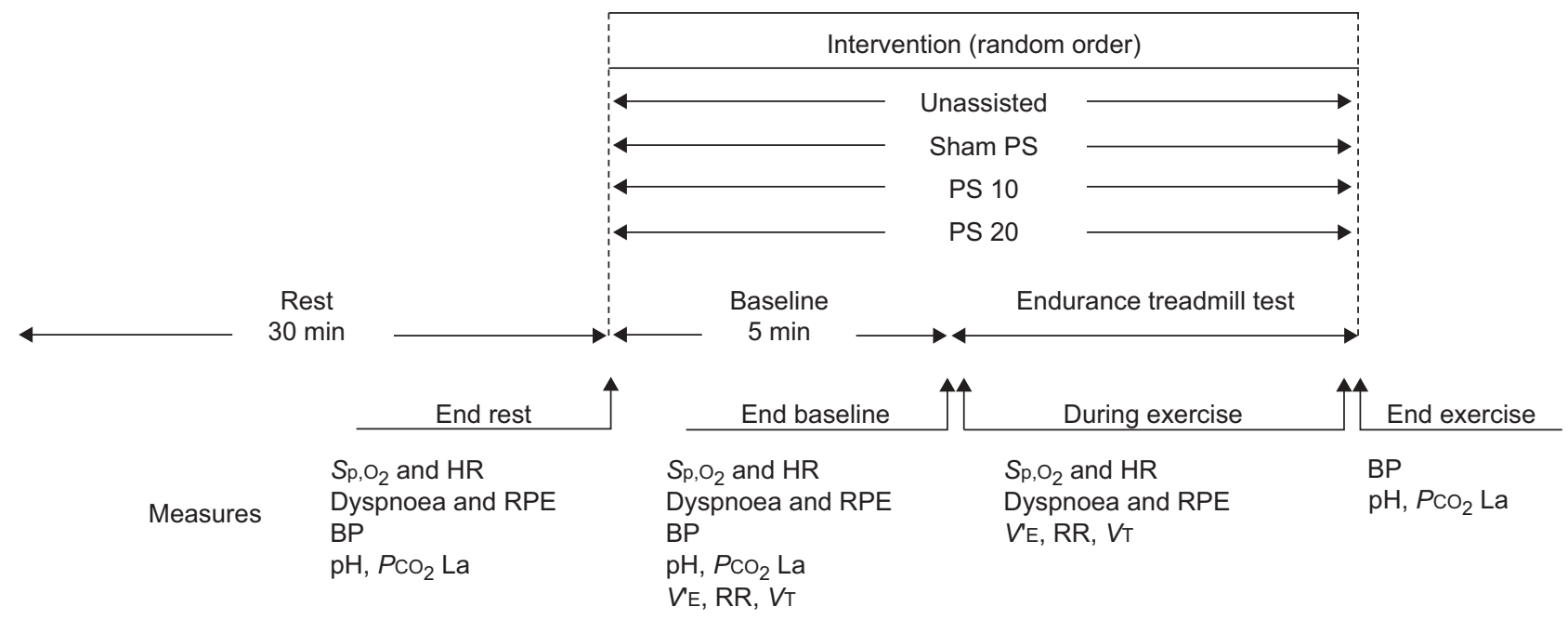

FIGURE 1. Study protocol and measures. Sham PS: sham pressure support; $\mathrm{PS}$ 10: pressure support at $10 \mathrm{cmH}_{2} \mathrm{O}$; $\mathrm{PS} 20$ : pressure support at $20 \mathrm{cmH} \mathrm{C}_{2} \mathrm{O}$; $\mathrm{Sp}, \mathrm{O}_{2}$ : oxygen saturation measured by pulse oximetry; $\mathrm{HR}$ : heart rate; RPE: rate of perceived exertion; $\mathrm{BP}$ : blood pressure; $\mathrm{PCO}_{2}$ : arterialised venous partial pressure of carbon dioxide; La: lactate; $V^{\prime} E$ : minute ventilation; RR: respiratory rate; $V T$ : tidal volume.

analysis. Descriptive data for continuous variables are presented as mean $\pm \mathrm{SD}$ or median (interquartile range). Linear mixed model analyses were performed to determine first if there was a difference between the four interventions (unassisted exercise, sham PS, PS 10 or PS 20) with respect to treadmill walking endurance time and, secondly, to determine if there was a difference between the four conditions at different time points (rest, isotime, end exercise and change from rest to end exercise) with respect to physiological and subjective variables. Isotime was defined as the duration of the shortest treadmill test. The effect of test order on primary and secondary outcome measures was also assessed. A significance level of $\alpha<0.05$ was used. If a significant difference was detected between the four interventions for a specific variable, pairwise comparisons were performed along with a sharper Bonferroni correction of p-values [16].

\section{RESULTS}

\section{Participants}

13 participants (seven females) with severe kyphoscoliosis were recruited. Static lung volumes and MVV could not be measured in one participant due to intolerable dyspnoea while breathing on the mouthpiece. Therefore, data are reported for 12 participants. Participant characteristics are described in table 1.

\section{Endurance treadmill test}

Endurance time

Mean treadmill walking speed was $2.9 \pm 0.6 \mathrm{~km} \cdot \mathrm{h}^{-1}$ (median (interquartile range) intensity $80 \%(75-80 \%)$ of $2 \mathrm{MWT}$ average walking speed). Individual and group endurance time data for each of the four interventions are displayed in figure 2. Endurance time data were not normally distributed and were transformed using $\log (x)$ prior to analysis. There was a difference in endurance time between walking unassisted, with sham PS, PS 10 and PS $20(\mathrm{p}=0.02)$. Pairwise comparisons revealed that PS 20 (median (interquartile range) 217 (168424) s) significantly increased endurance time compared with walking unassisted (139 (111-189) s), walking with sham PS
(103 (88-155) s) and walking with PS 10 (159 (131-206) s) after correction for multiple comparisons using a sharper Bonferroni adjustment [16]. Endurance time was also greater with PS 10 compared with sham PS (table 4 in the online supplementary material). There was no effect of test order on endurance time.

Physiological and subjective responses to PS during exercise Ventilation data were lost for one participant therefore minute ventilation $\left(V^{\prime} \mathrm{E}\right)$, tidal volume $(V \mathrm{~T})$ and respiratory rate are reported for 12 participants. Three participants used $1 \mathrm{~L} \cdot \mathrm{min}^{-1}$ of supplemental $\mathrm{O}_{2}$ during the treadmill tests as room air $\mathrm{Sp}, \mathrm{O}_{2}$ was $<89 \%$ at rest. During unassisted exercise, four participants breathed via an oronasal mask and eight via a mouthpiece. While breathing unassisted at rest prior to each endurance treadmill test, there were no differences between interventions with respect to $\mathrm{Sp}_{\mathrm{p}} \mathrm{O}_{2}$, cardiovascular variables, dyspnoea, $\mathrm{RPE}$, lactate or arterialised venous $\mathrm{pH}$ and $\mathrm{PCO}_{2}$ (see online supplementary material). There was no effect of test order on any of the physiological or subjective outcome measures.

At isotime exercise, there was a difference between interventions with respect to $S p, O_{2}(p<0.001)$, dyspnoea $(p=0.006), R P E$ $(p=0.013)$, respiratory rate $(p<0.001)$ and $V \mathrm{~T} \quad(p=0.018)$. Pairwise comparisons of the four interventions are shown in table 2 and figure 3 . A moderate inverse correlation was found between the change in endurance time and the change in isotime dyspnoea with PS 20 during walking compared with unassisted exercise (Spearman's rho -0.651, $p=0.016$; fig. 4). At end exercise, there was a difference between interventions with respect to diastolic BP $(p=0.02)$, mean arterial pressure $(p=0.007)$, lactate $(p=0.002)$, respiratory rate $(p<0.001), V T$ $(\mathrm{p}=0.003)$ and $V^{\prime} E(\mathrm{p}=0.015)$. Pairwise comparisons of the four interventions are reported in table 3 . The mean ratio of peak $V^{\prime}$ E during unassisted exercise to MVV was $95 \pm 49 \%$. The primary symptom at end exercise for each intervention is reported in figure 5 . Further data can be found in the online supplementary material. 


\begin{tabular}{|c|c|c|}
\hline & Value & $\%$ predicted \\
\hline Age yrs & $59(55-62)$ & \\
\hline Height $\mathbf{m}$ & $1.46 \pm 0.10$ & \\
\hline Arm span m & $1.66 \pm 0.15$ & \\
\hline $\mathrm{BMI} \mathbf{k g} \cdot \mathrm{m}^{-2}$ & $25.3 \pm 5.2$ & \\
\hline \multicolumn{3}{|l|}{ Resting ABG } \\
\hline $\mathrm{pH}$ & $7.40(7.36-7.42)$ & \\
\hline $\mathrm{Pa}, \mathrm{CO}_{2} \mathrm{mmHg}$ & $48.6(46.0-56.1)$ & \\
\hline $\mathrm{Pa}, \mathrm{O}_{2} \mathrm{mmHg}$ & $67.5(60.0-79.0)$ & \\
\hline $\mathrm{HCO}_{3}^{-} \mathrm{mmol} \cdot \mathrm{L}^{-1}$ & $30.0 \pm 2.3$ & \\
\hline $\mathrm{Sa}_{1} \mathrm{O}_{2} \%$ & $93.4 \pm 2.9$ & \\
\hline Supplemental $\mathrm{O}_{2} \mathrm{~L} \cdot \mathrm{min}^{-1}$ & $0(0-0.5)$ & \\
\hline \multicolumn{3}{|l|}{ Pulmonary function } \\
\hline FEV1 L & $0.51(0.48-0.62)$ & $20 \pm 6$ \\
\hline FVC L & $0.72 \pm 0.31$ & $22 \pm 7$ \\
\hline $\mathrm{FEV}_{1} / \mathrm{FVC} \%$ & $83(74-88)$ & \\
\hline$P \max 1.0 \mathrm{cmH}_{2} \mathrm{O}$ & $-34.8 \pm 15.5$ & $45 \pm 19$ \\
\hline$P E \max 1.0 \mathrm{cmH}_{2} \mathrm{O}$ & $87.7 \pm 45.0$ & $78 \pm 33$ \\
\hline $\mathrm{MVV} L \cdot \mathrm{min}^{-1}$ & $23.7 \pm 6.1$ & $23 \pm 5$ \\
\hline TLC L & $1.916 \pm 1.030$ & $35 \pm 15$ \\
\hline FRC L & $1.379 \pm 0.810$ & $46 \pm 23$ \\
\hline IC L & $0.537 \pm 0.256$ & $22 \pm 9$ \\
\hline$R V L$ & $1.131 \pm 0.708$ & $57 \pm 31$ \\
\hline \multicolumn{3}{|l|}{ Domiciliary NIV } \\
\hline Time on NIV yrs & $11.9 \pm 4.7$ & \\
\hline Compliance $\mathrm{h}$ per night & $8.9 \pm 2.6$ & \\
\hline Pressure/volume preset devices & $11 / 2$ & \\
\hline IPAP $^{\#} \mathrm{cmH}_{2} \mathrm{O}$ & $17.0 \pm 2.4$ & \\
\hline $\mathrm{EPAP}^{\#} \mathrm{cmH}_{2} \mathrm{O}$ & $6.0 \pm 1.1$ & \\
\hline $\mathrm{PS}^{\#} \mathrm{cmH}_{2} \mathrm{O}$ & $11.0 \pm 2.9$ & \\
\hline$V T^{*} L$ & $0.650 \pm 0.212$ & \\
\hline Nocturnal supplemental $\mathrm{O}_{2}{ }^{\circ} \mathrm{L} \cdot \mathrm{min}^{-1}$ & $3.0(2.0-4.0)$ & \\
\hline
\end{tabular}

Data are presented as mean \pm SD or median (interquartile range). BMI: body mass index; $\mathrm{ABG}$ : arterial blood gas; $\mathrm{Pa}_{\mathrm{a}} \mathrm{CO}_{2}$ : arterial carbon dioxide tension; $\mathrm{Pa}, \mathrm{O}_{2}$ : arterial oxygen tension; $\mathrm{Sa}_{1} \mathrm{O}_{2} \%$ : arterial oxygen saturation; $\mathrm{FEV}_{1}$ : forced expiratory volume in $1 \mathrm{~s}$; FVC: forced vital capacity; PImax1.0: maximal inspiratory mouth occlusion pressure over $1 \mathrm{~s}$; PEmax1.0: maximal expiratory mouth occlusion pressure over $1 \mathrm{~s}$; MVV: maximum voluntary ventilation; TLC: total lung capacity; FRC: functional residual capacity; IC: inspiratory capacity; RV: residual volume; NIV: noninvasive ventilation; IPAP: inspiratory positive airway pressure; EPAP: expiratory positive aimay pressure; PS: pressure support (difference between IPAP and EPAP); VT: tidal volume. ${ }^{\#}: n=11 ;{ }^{\circ}: n=2$.

\section{DISCUSSION}

To our knowledge, this study is the first double-blind, randomised, crossover study to examine the effects of different levels of PS during exercise in severe kyphoscoliosis. The main finding was that high-level PS $\left(2 \mathrm{cmH}_{2} \mathrm{O}\right)$ during treadmill walking significantly increased exercise endurance time compared with walking unassisted, with sham PS or low-level PS $\left(10 \mathrm{cmH}_{2} \mathrm{O}\right)$. Endurance time was also increased with PS 10 compared with sham PS. In addition, PS 20 during walking improved isotime $\mathrm{Sp}_{\mathrm{p}} \mathrm{O}_{2}$, reduced respiratory rate and leg muscle fatigue, and decreased dyspnoea compared with walking unassisted.

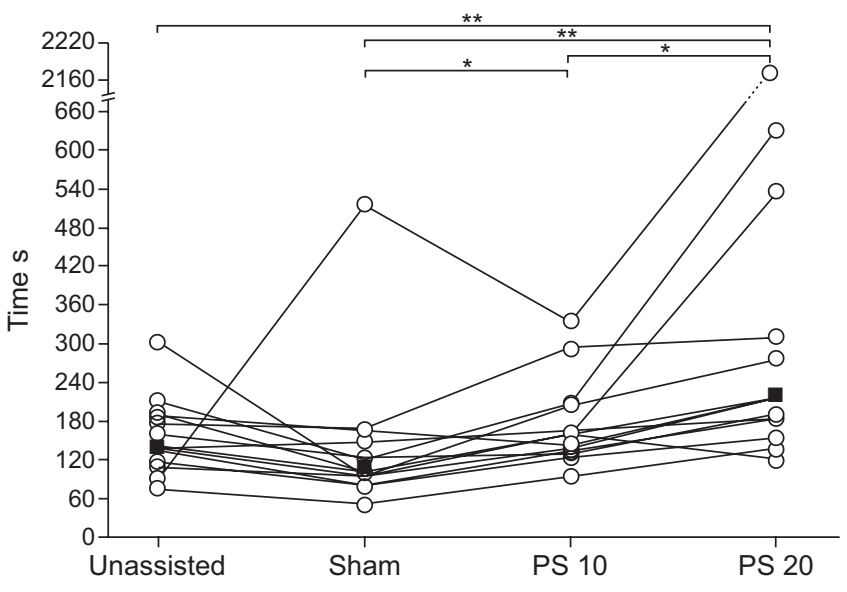

FIGURE 2. Treadmill test endurance times for unassisted exercise, walking with sham pressure support, pressure support at $10 \mathrm{cmH}_{2} \mathrm{O}$ (PS 10) and pressure support at $20 \mathrm{cmH}_{2} \mathrm{O}$ (PS 20). $\mathrm{O}$ : individual data; $\mathbf{\square}$ : medians. *: $\mathrm{p}<0.05$; **: $p<0.01$ after a sharper Bonferroni correction [16]

\section{Effect of high- and low-level PS during exercise on endurance time}

Our finding that high-level PS $\left(20 \mathrm{cmH}_{2} \mathrm{O}\right)$ during treadmill walking improved endurance time is consistent with other studies that have found that similar or higher levels of PS (19$37 \mathrm{cmH}_{2} \mathrm{O}$ ) during cycling exercise increased endurance time compared with unassisted exercise in individuals with chronic respiratory failure, primarily due to kyphoscoliosis [2], or pulmonary tuberculosis sequelae [17]. In the present study, treadmill exercise was performed rather than cycling exercise, as treadmill walking closely resembles a functional daily activity. However, walking is more likely to be limited by breathlessness [18], and a greater degree of $\mathrm{O}_{2}$ desaturation tends to occur in comparison to cycling exercise [19]. Therefore, our finding that high-level PS improves treadmill walking endurance time may be important when considering the specificity of training for a functional task such as walking.

Our finding that low-level PS $\left(10 \mathrm{cmH}_{2} \mathrm{O}\right)$ did not increase exercise endurance time compared with unassisted exercise is consistent with the study of HiGHCOCK et al. [8], who also found that low-level PS during treadmill walking did not improve distance walked compared with unassisted exercise in eight people with severe scoliosis. As chest wall compliance is greatly reduced in severe kyphoscoliosis [20], high inflationary pressures may be required to achieve an adequate $V \mathrm{~T}$ and to unload the respiratory muscles. Respiratory muscle unloading appears crucial for NIV to be of benefit during exercise in people with chronic obstructive pulmonary disease (COPD) [21] and, therefore, relatively low levels of PS during exercise may not unload the respiratory muscles sufficiently to assist exercise performance in individuals with severe kyphoscoliosis. In contrast to the studies cited above, the advantage of the present study was that we examined the effect of both highand low-level PS during exercise in the same subjects. Furthermore, both participants and assessors were blinded to the level of PS provided during exercise, thereby reducing the risk of bias. 


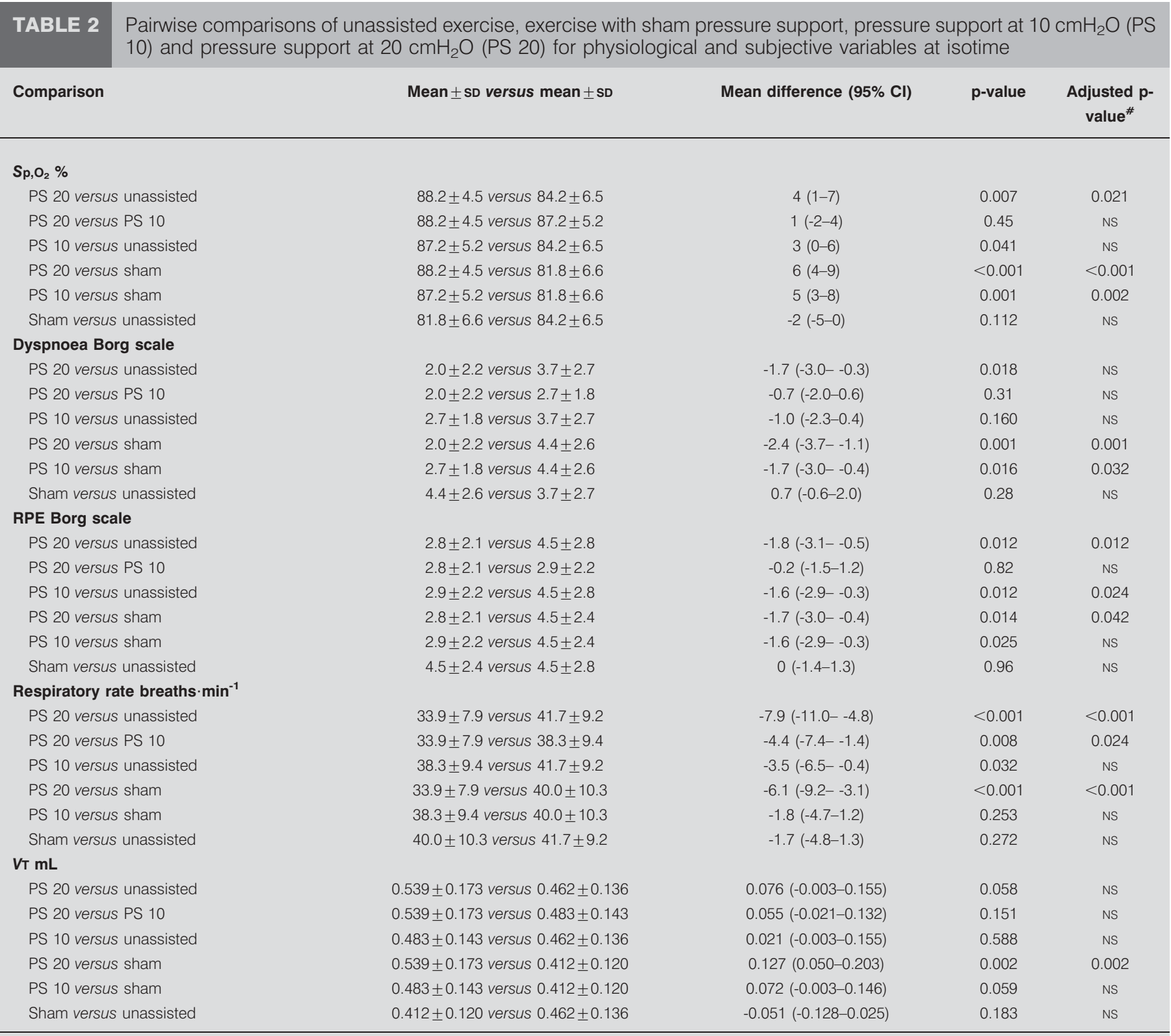

$\mathrm{Sp}, \mathrm{O}_{2}$ : oxygen saturation measured by pulse oximetry; RPE: rate of perceived exertion; $V \mathrm{~T}$ : tidal volume; NS: nonsignificant. ${ }^{\#}$ : $\mathrm{p}$-value adjusted using a sharper Bonferroni correction [16].

While the combination of NIV and $\mathrm{O}_{2}$ during exercise has previously been shown to improve endurance time above that of NIV or $\mathrm{O}_{2}$ alone during exercise in patients with severe chest wall restriction secondary to post-tuberculosis sequelae [17], no consistent effect on endurance time was observed in the three subjects who used supplemental $\mathrm{O}_{2}$ in the present study. For example, the change in endurance time with PS 20 plus $\mathrm{O}_{2}$ compared with unassisted exercise with $\mathrm{O}_{2}$ ranged between $-37 \%$ and $90 \%$ for these individuals, which spanned the results from the whole group (fig. 4). However, a larger sample size would be required to draw definitive conclusions about the effect of PS plus $\mathrm{O}_{2}$ during exercise in people with severe kyphoscoliosis.

\section{Potential mechanisms of benefit of high-level PS during exercise}

The mechanisms by which PS 20 increased exercise endurance time may relate to the improvement in pattern of breathing and oxygenation, and the reduction in dyspnoea and leg muscle fatigue that were demonstrated. One striking effect of PS 20 during exercise was the marked reduction in respiratory rate at isotime compared to sham PS, PS 10 and unassisted exercise. Despite exercising for longer with PS 20 compared with unassisted exercise, the reduction in respiratory rate of almost 8 breaths $\cdot \min ^{-1}$ was also maintained at end exercise. Surprisingly, only a small increase in $V$ T was observed with PS 20 compared with unassisted exercise, such that overall $V^{\prime} \mathrm{E}$ 

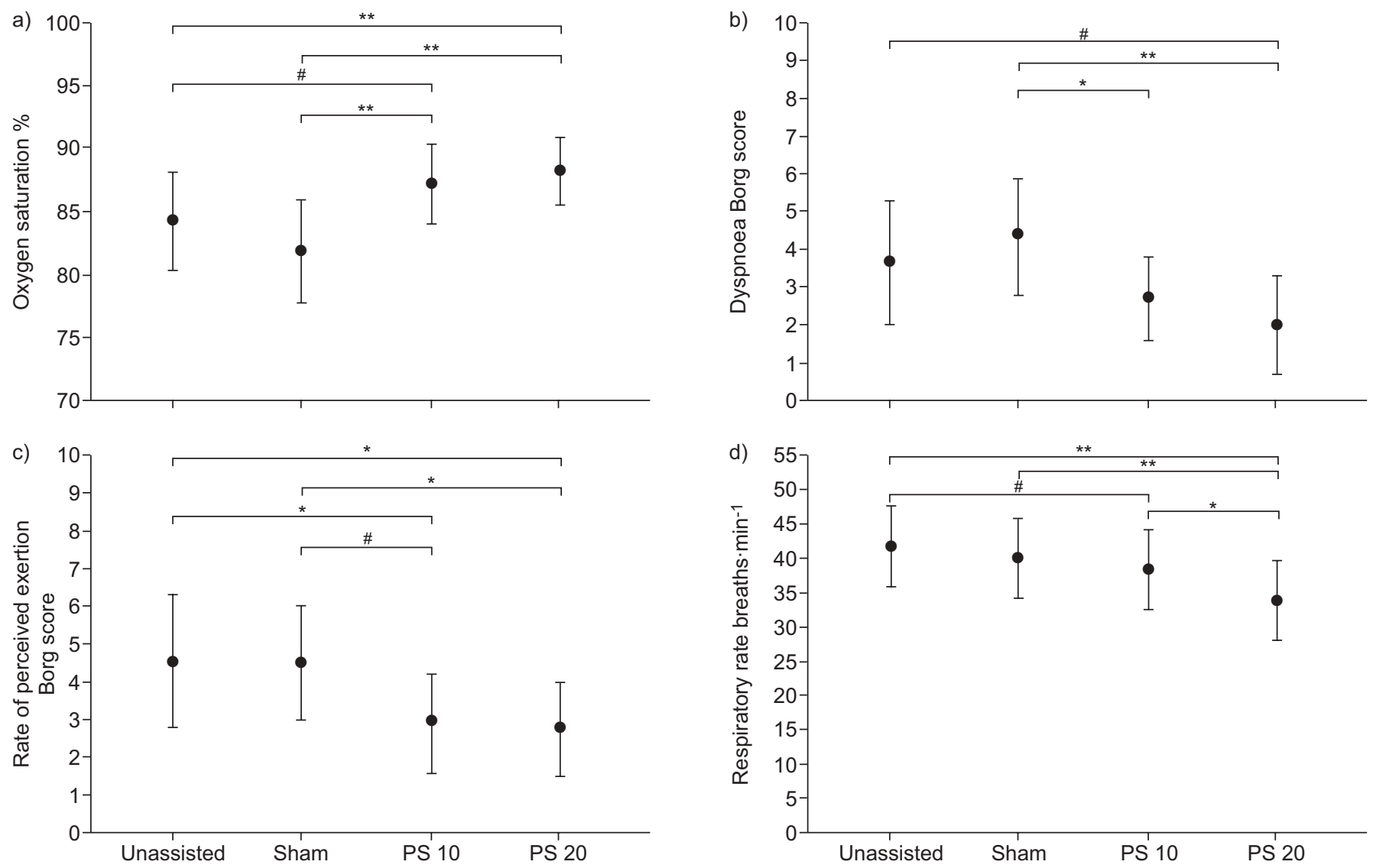

FIGURE 3. Comparison of unassisted exercise, exercise with sham pressure support, pressure support at $10 \mathrm{cmH}_{2} \mathrm{O}(\mathrm{PS} 10)$ and pressure support at $20 \mathrm{cmH} \mathrm{H}_{2} \mathrm{O}(\mathrm{PS} 20)$ at isotime for: a) oxygen saturation; b) dyspnoea; c) rate of perceived exertion; and d) respiratory rate. Group mean is shown for each condition and the error bars represent 95\% confidence intervals. *: $p<0.05$; ${ }^{* *}: p<0.01$ after the sharper Bonferroni correction [16]. *: $p<0.05$ prior to the sharper Bonferroni correction [16].

did not significantly change. Nonetheless, by adopting a more efficient pattern of breathing, dead space ventilation would be reduced and gas exchange improved [22].

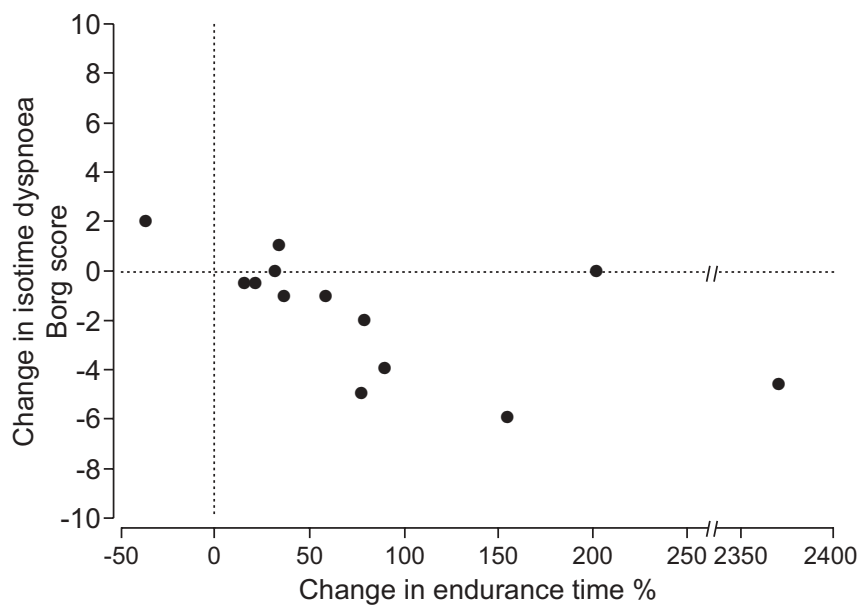

FIGURE 4. Relationship between the change in isotime dyspnoea (Borg scale) and the change in endurance time (\%) during walking with pressure support $20 \mathrm{cmH}_{2} \mathrm{O}$ compared with unassisted exercise. $\mathrm{r}_{\mathrm{S}}=-0.651 ; \mathrm{p}=0.016$
People with severe kyphoscoliosis and chronic respiratory failure also develop a combined respiratory and metabolic acidosis during exercise [22], which could impair respiratory muscle function $[23,24]$. We found that end exercise $\mathrm{pH}$ and $\mathrm{PCO}_{2}$ were no worse with PS 20 compared with the other three conditions, despite subjects having exercised for longer with PS 20. This suggests that PS 20 delayed the development of exercise-induced hypercapnia compared with unassisted exercise, consistent with the findings of VILA et al. [22]. At end exercise, blood lactate was significantly higher with PS 20 compared with sham PS, and tended to be greater than with unassisted exercise or PS 10. This is likely to reflect the longer endurance time associated with PS 20 compared with the other interventions.

Isotime $\mathrm{Sp}_{\mathrm{O}} \mathrm{O}_{2}$ was higher with PS 20, and to a lesser extent with PS 10, compared with unassisted exercise and sham PS. Consequently, increased $\mathrm{O}_{2}$ delivery to the peripheral muscles may have contributed to the improved performance with PS 20. It was surprising that isotime $S_{\mathrm{p}}, \mathrm{O}_{2}$ was higher with PS 20 compared with unassisted exercise, given the marked fall in respiratory rate, small rise in $V \mathrm{~T}$, and small fall in $V^{\prime} \mathrm{E}$ that was observed with PS 20. However, even though $V^{\prime} \mathrm{E}$ was higher during unassisted exercise, dead space ventilation was also likely to be higher due to the faster respiratory rate and, 


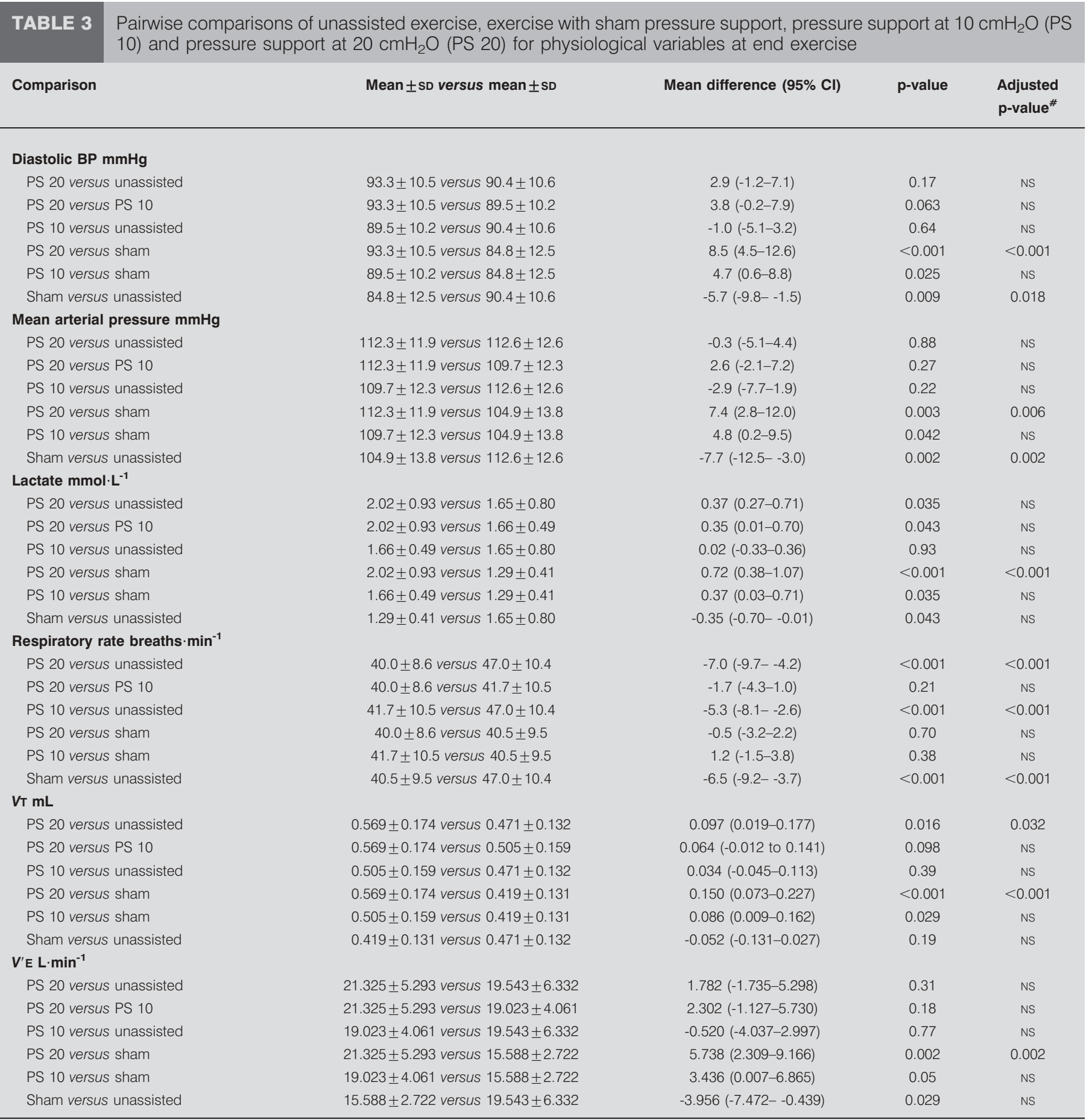

BP: blood pressure; VT: tidal volume; V'E: minute ventilation; NS: nonsignificant. ${ }^{\#}$ : p-value adjusted using a sharper Bonferroni correction [16].

therefore, alveolar ventilation may not have increased as might have been expected. Also, no consistent pattern was observed between individual changes in $V^{\prime} \mathrm{E}$ and isotime $S_{\mathrm{p}}, \mathrm{O}_{2}$, suggesting that factors other than an increase in $V^{\prime} \mathrm{E}$ contributed to the improvement in isotime $\mathrm{Sp}_{\mathrm{p}} \mathrm{O}_{2}$ with PS 20 in some individuals. A major improvement in ventilation-perfusion matching is an unlikely explanation, although the short-term effect of PS on ventilation-perfusion matching has not been assessed in severe kyphoscoliosis. It is possible that PS 20 unloaded the respiratory muscles and reduced the $\mathrm{O}_{2}$ cost of breathing $\left(V_{\mathrm{O}_{2}}\right.$,resp) compared with unassisted exercise, resulting in a higher $\mathrm{Sp}_{\mathrm{p}} \mathrm{O}_{2}$ at isotime. The $V_{2}$,resp can represent a substantial proportion of total oxygen consumption in patients with cardiorespiratory disease [25]. In severe COPD, NIV has been shown to unload the respiratory muscles during exercise $[21,26]$. Whether the same effect occurs in severe kyphoscoliosis remains to be 


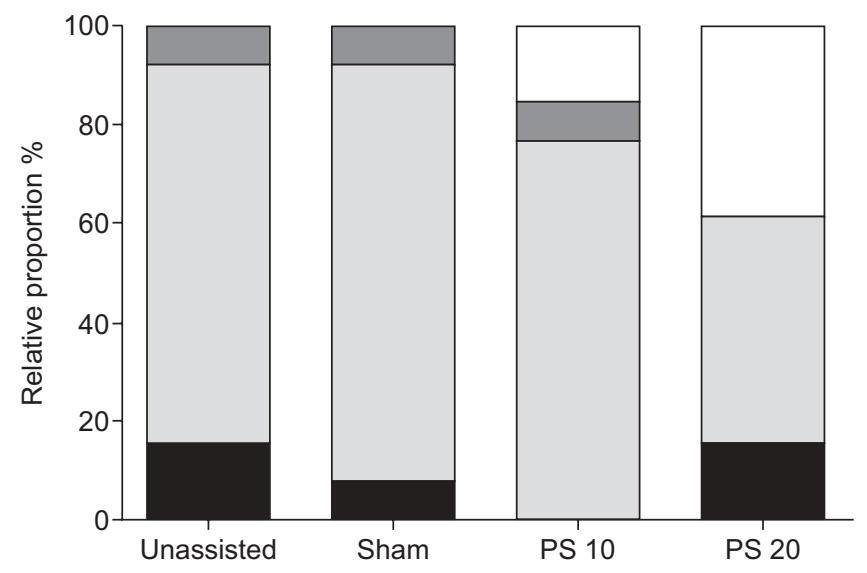

FIGURE 5. Column graph demonstrating the relative proportion of participants $(n=13)$ who ceased exercise primarily due to leg muscle fatigue $(\square)$, shortness of breath and leg muscle fatigue $(\square)$, shortness of breath alone $(\square)$ or oxygen desaturation below $75 \%$ ( $\mathbf{\square}$ ) for endurance treadmill tests performed unassisted, or with sham pressure support, pressure support $10 \mathrm{cmH}_{2} \mathrm{O}$ (PS 10) and pressure support $20 \mathrm{cmH}_{2} \mathrm{O}$ (PS 20).

demonstrated. Finally, despite endurance time being greater with PS 20, there was no difference in end exercise $S \mathrm{p}, \mathrm{O}_{2}$ between conditions, indicating that participants performed more exercise with PS 20 before reaching the same level of $\mathrm{O}_{2}$ desaturation.

Although detailed assessment of the effect of PS during exercise on the cardiovascular system was beyond the scope of the present study, one potential side-effect of high-level PS is a reduction in venous return, which may also decrease cardiac output. We found no change in heart rate at isotime exercise between conditions, and end exercise mean arterial pressure was not reduced with PS 20 compared with sham PS, PS 10 or unassisted exercise, suggesting that no observable detrimental cardiovascular effects of high-level of PS occurred. However, a previous study showed that people with thoracic scoliosis develop exercise-induced pulmonary hypertension (PH) inversely proportional to vital capacity, functional residual capacity and total lung capacity [27]. Subjects in the present study had significantly reduced static lung volumes and may have been at risk of developing severe exerciseinduced $\mathrm{PH}$. In COPD, $\mathrm{PH}$ limits stroke volume during exercise [28] and has a detrimental effect on exercise capacity [29]. While long-term nocturnal NIV was found to reduce PH in people with severe restrictive thoracic disorders [30], presumably through the reversal of hypoxaemia and hypercapnia, the acute effect of high-level PS on the development of exercise-induced $\mathrm{PH}$ and the resultant effect on stroke volume and exercise tolerance is unknown in patients with severe kyphoscoliosis, but may warrant investigation.

Subjective responses to PS during exercise largely reflected the physiological responses to PS during exercise. By reducing unpleasant symptoms, such as breathlessness and leg muscle fatigue, PS 20 enabled participants to tolerate exercise for longer. Isotime dyspnoea was reduced by both PS 20 and PS 10 compared with sham PS. PS 20 also reduced isotime dyspnoea by a mean of almost two points on the Borg scale compared with unassisted exercise. The reduction in isotime dyspnoea appeared to be an important mechanism influencing the exercise response during PS 20, with those subjects with a greater reduction in dyspnoea tending to have a greater increase in endurance time with PS 20 (fig. 5). Knowledge of this relationship may assist clinicians to titrate optimal, individualised high levels of PS during walking in people with severe kyphoscoliosis, in order to maximise the response to PS during exercise. Almost half of the participants during PS 20 stopped exercise due to leg muscle fatigue rather than breathlessness (fig. 5). This suggests that the reduction in breathlessness allowed a greater amount of work to be performed by the locomotor muscles, to the point of leg muscle fatigue in some cases, which may be important during exercise training. Likewise, isotime RPE was reduced by a mean of almost two points on the Borg scale with PS 20 and PS 10 compared with unassisted exercise and sham PS, with a slightly greater effect observed with PS 20. This lower perception of respiratory and locomotor effort during exercise most likely allowed participants to tolerate exercise for longer.

\section{Limitations}

The authors acknowledge the difficulty of blinding participants and assessors to the different levels of PS used in the present study. Every attempt was made to achieve blinding, including the randomisation of test order and concealment of ventilator settings from assessors and participants. None of the participants had used CPAP prior to the present study, and participants were not aware of the PS levels being tested or the study hypothesis. In addition, the instructions and encouragement given to participants was standardised to reduce potential bias.

\section{Clinical implications}

The findings of this study provide evidence that the efficacy of PS during exercise in severe kyphoscoliosis depends on the level of PS provided. Identification of ventilator settings that provide the greatest improvement in exercise performance is important if PS is to be used as an adjunct to exercise training, or to assist in the performance of daily activities. Whether even higher levels of PS could result in greater improvements in exercise performance is unknown. However, the delivery of very high levels of PS may be limited by mask leak, patient discomfort and the possible cardiovascular consequences of larger positive intrathoracic pressure. Patient selection may also affect the response to PS during exercise. The current study demonstrated the efficacy of high-level PS in severe chest wall restriction, a finding supported by BOREL and Coworkers [2,31], who showed that subjects with severe chest wall restriction had a greater response to high-level PS during exercise compared with those with moderate restriction. In addition, ventilator capacity [8] and choice of interface may impact on an individual's response to NIV-assisted exercise.

\section{Conclusion}

High-level PS $\left(20 \mathrm{cmH}_{2} \mathrm{O}\right)$ during treadmill walking in people with severe kyphoscoliosis increases endurance time, improves pattern of breathing and oxygenation, and reduces the perception of leg muscle fatigue and dyspnoea compared with unassisted exercise. Low-level PS $\left(10 \mathrm{cmH}_{2} \mathrm{O}\right)$ did not increase endurance time compared with unassisted exercise, 
indicating that the level of PS provided during exercise influences the efficacy of the intervention. Investigation of the role of high-level PS during exercise training or during daily activities in subjects with severe chest wall restriction who demonstrate an acute improvement in exercise performance with PS is warranted.

\section{CLINICAL TRIAL}

The study was registered with the Australian New Zealand Clinical Trials Registry (ACTRN12608000155392).

\section{STATEMENT OF INTEREST}

Statements of interest for C. Menadue, A.J. Piper, K.K. Wong and C. Hollier can be found at www.erj.ersjournals.com $/ \mathrm{misc} /$ statements.dtl

\section{ACKNOWLEDGEMENTS}

The authors would like to acknowledge G. Unger (Woolcock Institute of Medical Research, The University of Sydney, Sydney, Australia) and D. Flunt (Royal Prince Alfred Hospital, Sydney, Australia) for technical assistance.

\section{REFERENCES}

1 Shneerson JM. The cardiorespiratory response to exercise in thoracic scoliosis. Thorax 1978; 33: 457-463.

2 Borel JC, Wuyam B, Chouri-Pontarollo N, et al. During exercise non-invasive ventilation in chronic restrictive respiratory failure. Respir Med 2008; 102: 711-719.

3 Meecham Jones DJ, Paul EA, Bell JH, et al. Ambulatory oxygen therapy in stable kyphoscoliosis. Eur Respir J 1995; 8: 819-823.

4 Fuschillo S, De Felice A, Gaudiosi C, et al. Nocturnal mechanical ventilation improves exercise capacity in kyphoscoliotic patients with respiratory impairment. Monaldi Arch Chest Dis 2003; 59: 281-286.

5 Schonhofer B, Wallstein S, Wiese C, et al. Noninvasive mechanical ventilation improves endurance performance in patients with chronic respiratory failure due to thoracic restriction. Chest 2001; 119: 1371-1378.

6 Schonhofer B, Ardes P, Geibel M, et al. Evaluation of a movement detector to measure daily activity in patients with chronic lung disease. Eur Respir J 1997; 10: 2814-2819.

7 Schonhofer B, Zimmermann C, Abramek P, et al. Non-invasive mechanical ventilation improves walking distance but not quadriceps strength in chronic respiratory failure. Respir Med 2003; 97: 818-824.

8 Highcock MP, Smith IE, Shneerson JM. The effect of noninvasive intermittent positive-pressure ventilation during exercise in severe scoliosis. Chest 2002; 121: 1555-1560.

9 Butland RJ, Pang J, Gross ER, et al. Two-, six-, and 12-minute walking tests in respiratory disease. Br Med J (Clin Res Ed) 1982; 284: 1607-1608.

10 Quanjer PH, Tammeling GJ, Cotes JE, et al. Lung volumes and forced ventilatory flows. Report Working Party Standardization of Lung Function Tests, European Community for Steel and Coal. Official Statement of the European Respiratory Society. Eur Respir J Suppl 1993; 16: 5-40.

11 Wilson SH, Cooke NT, Edwards RH, et al. Predicted normal values for maximal respiratory pressures in caucasian adults and children. Thorax 1984; 39: 535-538.
12 Kory RC, Callahan R, Boren HG, et al. The Veterans Administration-Army cooperative study of pulmonary function. I. Clinical spirometry in normal men. Am J Med 1961; 30: 243-258.

13 Grimby G, Soderholm B. Spirometric studies in normal subjects. III. Static lung volumes and maximum voluntary ventilation in adults with a note on physical fitness. Acta Med Scand 1963; 173: 199-206.

14 Linderholm H, Lindgren U. Prediction of spirometric values in patients with scoliosis. Acta Orthop Scand 1978; 49: 469-474.

15 Borg GA. Psychophysical bases of perceived exertion. Med Sci Sports Exerc 1982; 14: 377-381.

16 Hochberg Y. A sharper Bonferroni procedure for multiple tests of significance. Biometrika, 1988: 800-802.

17 Tsuboi T, Ohi M, Chin K, et al. Ventilatory support during exercise in patients with pulmonary tuberculosis sequelae. Chest 1997; 112: 1000-1007.

18 Man WD, Soliman MG, Gearing J, et al. Symptoms and quadriceps fatigability after walking and cycling in chronic obstructive pulmonary disease. Am J Respir Crit Care Med 2003; 168: 562-567.

19 Turner SE, Eastwood PR, Cecins NM, et al. Physiologic responses to incremental and self-paced exercise in COPD: a comparison of three tests. Chest 2004; 126: 766-773.

20 Grassi V, Tantucci C. Respiratory prognosis in chest wall diseases. Monaldi Arch Chest Dis 1993; 48: 183-7.

21 Maltais F, Reissmann H, Gottfried SB. Pressure support reduces inspiratory effort and dyspnea during exercise in chronic airflow obstruction. Am J Respir Crit Care Med 1995; 151: 1027-1033.

22 Vila B, Servera E, Marin J, et al. Noninvasive ventilatory assistance during exercise for patients with kyphoscoliosis: a pilot study. Am J Phys Med Rehabil 2007; 86: 672-677.

23 Juan G, Calverley P, Talamo C, et al. Effect of carbon dioxide on diaphragmatic function in human beings. N Engl J Med 1984; 310: 874-879.

24 Jonville S, Delpech N, Denjean A. Contribution of respiratory acidosis to diaphragmatic fatigue at exercise. Eur Respir J 2002; 19: 1079-1086.

25 Field S, Kelly SM, Macklem PT. The oxygen cost of breathing in patients with cardiorespiratory disease. Am Rev Respir Dis 1982; 126: 9-13.

26 Kyroussis D, Polkey MI, Hamnegard CH, et al. Respiratory muscle activity in patients with COPD walking to exhaustion with and without pressure support. Eur Respir J 2000; 15: 649-655.

27 Shneerson JM. Pulmonary artery pressure in thoracic scoliosis during and after exercise while breathing air and pure oxygen. Thorax 1978; 33: 747-754.

28 Holverda S, Rietema H, Westerhof N, et al. Stroke volume increase to exercise in chronic obstructive pulmonary disease is limited by increased pulmonary artery pressure. Heart 2009; 95: 137-141.

29 Sims MW, Margolis DJ, Localio AR, et al. Impact of pulmonary artery pressure on exercise function in severe COPD. Chest 2009; 136: 412-419.

30 Schonhofer B, Barchfeld T, Wenzel M, et al. Long term effects of non-invasive mechanical ventilation on pulmonary haemodynamics in patients with chronic respiratory failure. Thorax 2001; 56: 524-528.

31 Borel JC, Verges S, Pepin JL, et al. Home exercise training with non-invasive ventilation in thoracic restrictive respiratory disorders: a randomised study. Respir Physiol Neurobiol 2009; 167: 168-173. 